\title{
Impact-ED - A New Model of Digital Library Impact Evaluation
}

\author{
Gemma Madle ${ }^{1}$, Patty Kostkova ${ }^{1}$, and Abdul Roudsari ${ }^{2}$ \\ ${ }^{1}$ City eHealth Research Centre, City University, London EC1V 0HB \\ ${ }^{2}$ Centre for Health Informatics, City University, London EC1V OHB \\ g.c.madle@city.ac.uk
}

\begin{abstract}
This paper presents Impact-ED, a new model for digital library impact evaluation. The model draws on assumptions from the Theory of Planned Behaviour and the Sense-Making Model. The paper discusses the current shortfalls of digital library impact evaluation and presents an alternative. Knowl- edge and attitude are put forward as potential measures of impact and different methods are triangulated and data linked to provide a comprehensive picture of the impact of the library at the time of use. The model shows how the digital library is being used to benefit users in their work, how it is changing their knowledge and attitudes and how the information found is used in real-time in the real world. It is being tested in the healthcare domain on the National Resource for Infection Control (www.nric.org.uk) but is expected to be transferable to other domains as further work will prove.
\end{abstract}

Keywords: Digital Library Evaluation, Sense-making, Knowledge and Attitudes, Impact Evaluation.

\section{Introduction}

Recent years have seen an explosion in the amount of money being spent on IT projects in healthcare [1,2]. Digital libraries have the potential to change working culture creating new types of professional relationships and communities based across distances, hierarchy and other traditional barriers. With this huge investment of public money it is surely important to investigate these changes and the impact of the resources provided on clinical care, decision-making and patient outcomes.

But what do we mean by impact and how can we measure it? Previous research in the 1980s and early 1990s has shown that physical hospital library services can contribute to patient care and clinical decision-making [3-5]. In one study Medline searches performed earlier in the patient's hospital stay were associated with lower costs, charges and length of stay than those whose searches were performed later [6]. There have been several papers discussing the impact of healthcare libraries, both physical and digital [4;7-10] and a systematic review of the effectiveness of tradi- tional libraries and clinical librarian programs on patient care [11] but development of methodologies is lacking. A recent systematic review of evaluations of the impact of healthcare digital libraries identified a need for new methodologies with most 

previous evaluations measuring impact with questionnaires and interviews, therefore relying on self-reported impact [12]. A healthcare digital library impact evaluation needs to show how the digital library is being used to benefit users in their work, how it is changing their knowledge and attitudes and how the information found is used. It needs to evaluate at the time of use not just retrospectively and activity within the library should be monitored. So far research has failed to achieve this [12].

This paper attempts to address this need by using the Theory of Planned Behaviour and Dervin's Sense-making model to develop and present a new model for digital library impact evaluation research based on knowledge and attitude change.

\section{The Impact-ED Model}

Fox and Marchionini [13] presented a model of digital library dimensions in 1999 based on the research in the field at that time. They suggested there are four dimen- sions to DL work: Community; Services; Technology; Content. DL impact evaluation should be measuring the impact of DL content, provided through the technology and services, on its community. Is use of the DL changing a clinician's work practice rather than just helping them on one or two occasions? Evaluation of DL impact should involve investigation into the longer-term effects on the user rather than just short-term changes in decision-making.

The requirements of a DL Impact Evaluation Model are set out below as they apply to each dimension of the DL. The aim of developing the model in this way was to

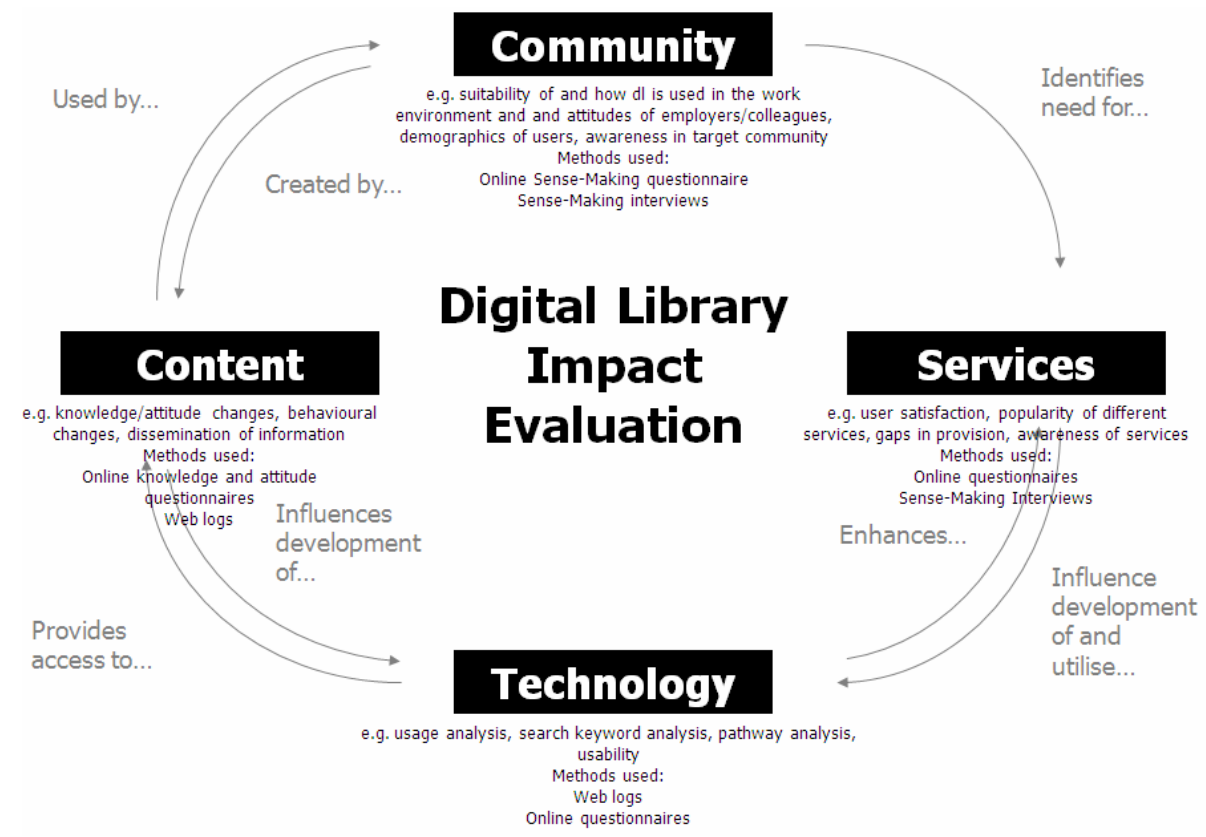

Fig. 1. The Impact-ED model 
ensure that evaluation is based around the function and purpose of a digital library as well as the community that it serves. The requirements were compiled following a review of the literature to identify impact evaluations of healthcare digital libraries and are published elsewhere[12]. In summary the ideal evaluation will not just evalu- ate self-reported knowledge, attitude and behaviour changes but actual changes, and changes that occur as a result of real-time, real use in the real world by real users. Data should be obtained from different methods and linked for individual users to obtain a more in-depth picture of digital library use and impact. The review of the literature [12] identified 12 healthcare DL evaluations ( 2 of the same DL). Only one of the studies evaluated real-time use of the DL at the point of need in the user's work and none linked data on an individual basis from different sources. Therefore a new model is required that meets these requirements and provides a template for imple- menting DL impact evaluations. Figure 1 shows the model.

The intention of the Impact-ED (Impact Evaluation for Digital Libraries) model is that a variety of methods are used to collect data and data is linked to provide a more rounded picture of a digital library impact. The model draws on assumptions from the Theory of Planned Behaviour [14] and techniques from Dervin's Sense-making model and methodology[15-17] which are described in more detail elsewhere [18]. The methods are as follows:

1. Online questionnaires - investigating use of the DL within the work environment

2. Online pre and post visit (sense-making) questionnaires - investigating realtime, real-world use and how knowledge and attitudes change

3. Online tasks - how users complete tasks to find information within the library and how this changes knowledge and attitudes

4. Web log analysis - shows what users actually did within the DL

5. Interviews - to compliment these other methods by providing more in-depth qualitative data that expands on issues identified in the questionnaires and web logs.

This provides a much more in-depth picture of how a digital library may be impacting its user community and their work than previous research has allowed. The variety of methods used allows all the requirements to be met. The next section discusses how these methods and this model are implemented using knowledge and attitude as measures of impact.

The model is currently being tested on the National Resource for Infection Control (NRIC). On completion of the study in June 2008 this information provided by users at the time of visiting the library will all be linked to user activity \& subsequent analysis will enable refinement of the framework and model i.e. adaptation of meth- ods used if necessary. An insight will be provided into how the different dimensions of the library have an impact on its users.

\section{Discussion}

Whilst more rounded and comprehensive than previous digital library impact re- search, currently the model does not include methods for measuring outcomes such as 
prescribing rates, length of inpatient stay etc. As discussed knowledge and attitude are only indicators of intended behaviour and actual behaviour is only being evaluated by the sense-making interviews but this will only be self-reported behaviour. How- ever, it would be possible to extend the model to include such measures, under the community dimension should there be opportunity to do so. The model has been developed within the healthcare domain and therefore the case study and scenarios used are healthcare focused. However, it should be possible to use the model in other domains as the methods described are non-subject specific but the ease of this has not yet been tested. In addition, there is no distinction between short-term and long-term impacts within the model. This is to allow the evaluator the flexibility to decide on this according to their needs and research constraints.

There are a variety of frameworks for digital library evaluation [19, 20-26], but all fall short of impact evaluation such as that presented by the model proposed. The key emphasis of most of these frameworks and their measures is on statistical measures e.g. usage statistics and satisfaction ratings. Therefore the new model presented in this paper differs from existing toolkits and frameworks in two main ways:

- It collects pre and post use data about purpose of use, knowledge and attitudes about the subject and expected impact at the point of the visit to the digital library.

- It links data from different methods to provide a picture of the impact the library has on individual users.

Its key features are:

- Universality - the aim is that this model should be able to be applied to any DL

- Objectivity - the model does not rely solely on self-reported data often subject to user perceptions but complements these by objectively collected data via Web server $\log s$

- Versatility - using and appropriately combining multiple data collection methods to gain a rich understanding of user knowledge, attitude and behaviour change as a result of use of a DL

\section{Conclusion and Future Work}

This paper has discussed the need for new methodologies for digital library impact evaluation and presented a new model, Impact-ED, that is being tested in the healthcare domain. The novel approach of this model is the evaluation of knowledge and attitude changes and it is based on assumptions from the theory of planned behaviour and uses Dervin's sense-making technique. It provides a comprehensive approach to impact evaluation with mixed methods and data linkage being key. It evaluates at the time of use and activity within the library is monitored. The model is currently being used in an evaluation of the National Resource for Infection Control digital library and will be refined accordingly when data is available. This new model provides a useful framework for evaluating user knowledge and attitude changes following use of a healthcare digital library and has the potential to be extended to include outcome measures such as prescribing rates and length of inpatient stay as well being transferable to other domains. Future research will include extension of the model to include these outcome measures as well as investigate longer-term impact. The aim is also to use the model on a non-healthcare library to test the applicability to other domains. 


\section{References}

1. National Program for IT, http://www.npfit.nhs.uk/default.asp

2. National Knowledge Service, http://www.nks.nhs.uk/

3. Marshall, J.G.: The Impact of the Hospital Library on Clinical Decision Making: The Rochester Study. Bull. Med. Libr. Assoc. 80, 169-178 (1992)

4. O'Connor, P.: Determining the Impact of Health Library Services on Patient Care: A Review of the Literature. Health Inf. Libr. J. 19, 1-13 (2002)

5. King, D.N.: The Contribution of Hospital Library Information Services to Clinical Care: A Study in Eight Hospitals. Bull. Med. Libr. Assoc. 75, 291-301 (1987)

6. Klein, M.S., Ross, F.V., Adams, D.L., Gilbert, C.M.: Determining the Impact of Health Library Services on Patient Care: A Review of the Literature. Acad. Med. 69, 489-495 (1994)

7. Cullen, R.: Evaluating Digital Libraries in the Health Sector. Part 2: Measuring Impacts and Outcomes. Health Inf. Libr. J. 21, 3-13 (2004)

8. Cullen, R.: Evaluating Digital Libraries in the Health Sector. Part 1: Measuring Inputs and Outputs. Health Inf. Libr. J. 20, 195-204 (2003)

9. Cullen, R., Esson, R.: Assessing the Impact of Information Services in the Health Sector. Health Inf. Libr. J. 24(s1), 1-3 (2007)

10. Urquhart, C.: Assessing Impact: Let Us Count the Ways? Libr. Inf. Update 4(12), 26 (2005)

11. Weightman, A.L., Williamson, J.: The Value and Impact of Information Provided Through Library Services for Patient Care: A Systematic Review. Health Inf. Libr. J. 22(1), 4-25 (2005)

12. Madle, G., Kostkova, P., Roudsari, A.: The Impact of Healthcare Digital Libraries: a Systematic Review of Evaluation Methods (in preparation, 2008)

13. Fox, E., Marchionini, G.: Progress Towards Digital Libraries: Augmentation Through Integration. Inform. Process. Manag. 35, 219-225 (1999)

14. Ajzen, I.: The Theory of Planned Behavior. Organ. Behav. Hum. Dec. 50, 179-211 (1991)

15. Dervin, B.: Audience as Listener and Learner, Teacher and Confidante: The Sense-Making Approach. In: Dervin, B., Foreman-Wernet, L., Lauterbach, E. (eds.) Sense-making Methodology Reader: Selected Writings of Brenda Dervin, pp. 215-232. Hampton Press, Cresskill (2003)

16. Dervin, B.: A Theoretic Perspective and Research Approach for Generating Research Helpful to Communication Practice. In: Dervin, B., Foreman-Wernet, L., Lauterbach, E. (eds.) Sense-making Methodology Reader: Selected Writings of Brenda Dervin, pp. 251268. Hampton Press, Cresskill (2003)

17. Dervin, B.: Sense-making Instrument. Sense-making Home Page,

http: //communication.sbs.ohio-state.edu/

sense-making/inst/idervin97tech.html

18. Madle, G., Kostkova, P., Roudsari, A.: Impact-ED: The development of a new Digital Library Evaluation Model (in preparation, 2008)

19. Evalued Toolkit, http://www.evalued.uce.ac.uk/index.htm

20. Choudhury, S., Hobbs, B., Lorie, M., Flores, N., Coleman, A., Martin, M., Kuhlman, D.L., McNair, J.H., Rhodes, W.A., Tipton, R., Agnew, G., Nicholson, D., Macgregor, G.: A Framework for Evaluating Digital Library Services. D-Lib. 8(7-8) (2002)

21. Digiqual Website, http://www.digiqual.org/digiqual/index.cfm

22. Conyers, A.: The E-measures Project: Developing Statistical Measures for Electronic Information Services. In: E-measures Conference (2004) 
23. Clarke, Z.: Equinox: Library Performance Measurement and Quality Management System. Learn. Res. J. 16(2), 28-31 (2000)

24. Miller, R., Schmidt, S.: E-metrics: Measures for Electronic Resources. In: 4th Northumbria International Conference on Performance Measurement in Libraries and Information Services, Washington, DC (2001)

25. Franklin, B., Plum, T.: Successful Web Survey Methodologies for Measuring the Impact of Networked Electronic Services (MINES for Libraries). IFLA 32(1), 28-40 (2006)

26. Reeves, T.C., Apedo, X., Young, H.W.: Evaluating Digital Libraries: A User Friendly Guide. National Science Digital Library (2003),

http://eduimpact.comm.nsdl.org/evalworkshop/UserGuideOct20.doc 